\title{
Association of type 2 diabetes mellitus and antidiabetic medication with risk of prostate cancer: a population-based case- control study
}

E. Lin ${ }^{1 *}$ (D) Hans Garmo ${ }^{1}$, Mieke Van Hemelrijck1, Jan Adolfsson ${ }^{2}$, Pär Stattin ${ }^{3}$, Björn Zethelius ${ }^{4}$ and Danielle Crawley ${ }^{1}$

\begin{abstract}
Background: Prostate cancer (PCa) and type 2 diabetes mellitus (T2DM) are prevalent conditions that often occur concomitantly. However, many aspects of the impact of T2DM, particularly the duration of T2DM and antidiabetic medications, on PCa risk are poorly understood.

Methods: To assess the association of duration of T2DM and antidiabetic medication with PCa risk, we designed a matched case-control study, including 31,415 men with PCa and 154,812 PCa-free men in Prostate Cancer data Base Sweden (PCBaSe) 4.1.

Results: Overall, a decreased risk of PCa was observed for men with T2DM (odds ratio (OR): $0.81,95 \%$ confidence interval (Cl): 0.78-0.84), as compared to men without T2DM. The decreased risk of PCa was consistently showed across duration of T2DM. With respect to use of antidiabetic drugs, this inverse association with duration was also found for all medications types, as compared to men without T2DM, including insulin, metformin and sulphonylurea (SU) (e.g. 3-<5 yr insulin OR:0.69, 95\%Cl:0.60-0.80; 3-<5 yr metformin OR: 0.82, 95\%Cl: 0.74-0.91; 3-< 5 yr SU OR: $0.72,95 \% \mathrm{Cl}: 0.62-0.83)$. When stratifying by PCa risk categories, this decreased risk was most evident for diagnosis of low and intermediate-risk PCa (low-risk OR: 0.65, 95\%Cl: 0.66-0.70, intermediate-risk OR: 0.80, 95\%Cl: 0.75-0.85).

Conclusions: The study showed an inverse association between pre-existing T2DM and PCa across different durations of T2DM and all types of T2DM medication received. This inverse association was most evident for lowand intermediate-risk PCa, suggesting that whilst T2DM and its medication may protect some men from developing PCa, the relationship warrants further study.
\end{abstract}

Keywords: Type 2 diabetes mellitus, Antidiabetic medication, Duration, Prostate cancer risk

\footnotetext{
* Correspondence: e.lin@kcl.ac.uk

'School of Cancer and Pharmaceutical Sciences, Translational Oncology and Urology Research (TOUR), King's College London, London, UK

Full list of author information is available at the end of the article
}

(c) The Author(s). 2020 Open Access This article is licensed under a Creative Commons Attribution 4.0 International License, which permits use, sharing, adaptation, distribution and reproduction in any medium or format, as long as you give appropriate credit to the original author(s) and the source, provide a link to the Creative Commons licence, and indicate if changes were made. The images or other third party material in this article are included in the article's Creative Commons licence, unless indicated otherwise in a credit line to the material. If material is not included in the article's Creative Commons licence and your intended use is not permitted by statutory regulation or exceeds the permitted use, you will need to obtain permission directly from the copyright holder. To view a copy of this licence, visit http://creativecommons.org/licenses/by/4.0/. The Creative Commons Public Domain Dedication waiver (http://creativecommons.org/publicdomain/zero/1.0/) applies to the data made available in this article, unless otherwise stated in a credit line to the data. 


\section{Background}

Prostate cancer (PCa) and type 2 Diabetes Mellitus (T2DM) are prevalent conditions that often occur concomitantly [1]. Pre-existing T2DM has been associated with a decreased risk of $\mathrm{PCa}$ in multiple observational studies [2-8]. Existing studies examining the association of antidiabetic medications with PCa risk have, however, produced inconsistent results. While some suggest an inverse association of antidiabetic medications, particularly metformin, with PCa risk [9-13], others suggest null associations [14-17]. These existing studies have not explored the effect of the duration of antidiabetic medications on PCa risk. Moreover, few studies have assessed the impact of antidiabetic medications on severity of $\mathrm{PCa}$ at the time of diagnosis, i.e. $\mathrm{PCa}$ risk categories.

In a previous study using Prostate Cancer data Base Sweden (PCBaSe) and the National Diabetes Register data, Fall et al. (2013) reported reduced risk of PCa across all $\mathrm{PCa}$ risk categories $(\mathrm{OR}=0.80,95 \% \mathrm{CI}=0.76-$ 0.86 ) for men with T2DM compared to men without T2DM, especially low-risk $\mathrm{PCa}(\mathrm{OR}=0.71,95 \% \mathrm{CI}=$ 0.64-0.80) [4]. Since 2013, the National Diabetes Register have improved completeness of their data. In addition, PCBaSe has now been linked to the National Prescribed Drug Register to assess what medications patients receive for T2DM. Here, we use updated PCBaSe data to examine the association between duration of T2DM and antidiabetic medications and PCa risk.

\section{Methods}

\section{Participants}

We conducted a case-control study using PCBaSe 4.1 which is based on the National Prostate Cancer Register (NPCR) of Sweden, a nationwide population-based register starting in 1998 that includes more than $98 \%$ of the men registered with $\mathrm{PCa}$ in the National Cancer Register. NPCR contains detailed data on cancer characteristics including prostate-specific antigen (PSA) at the time of diagnosis, staging and Gleason Grade Groups [18]. Using the unique personal identity number given to all residents in Sweden, all participants have been subsequently linked to Swedish health care registers and demographic databases. These include the National Patient Register and Longitudinal integrated database for health insurance and labour market studies, to obtain data on co-morbidities, civil status and educational level in 2008 [18]. Comorbidities were quantified using the Charlson Comorbidity Index (CCI), based on discharge diagnoses in the In-Patient Registry with different weights $(1,2,3$ and 6$)$ to each ICD code $[19,20]$. For the current study, diabetes was not included in the CCI.

For every case in $\mathrm{PCBaSe}$, five $\mathrm{PCa}$-free control men $(n=154,812)$ were randomly selected from the general
Swedish population by use of the personal identity number [21], matched on year of birth and county of residence. The National Diabetes Register was initiated in 1996, and data records were linked via the personal identity number to PCBaSe [1]. In 2013, approximately $92 \%$ of the prevalent cases of type 1 and type 2 diabetes mellitus were included in the National Diabetes Register. We also used data from the National Prescribed Drug Register. The National Prescribed Drug Register was established in July 2005 and contains all prescribed drugs dispensed at pharmacies in Sweden.

\section{Identification of men with T2DM}

To investigate the association between T2DM and $\mathrm{PCa}$, we assessed data related to T2DM diagnosis and drug treatments available in the National Diabetes Register and National Prescribed Drug Register. We defined preexisting T2DM as fulfilling at least one of following criteria:

1) a medical record of the year of T2DM onset in the National Diabetes Register

2) a registration date of T2DM in the National Diabetes Register

3) a prescription for antidiabetic drugs (at least two filled prescriptions records) in the National Prescribed Drug Register.

\section{Exposure}

The primary exposure was duration of T2DM. The duration of T2DM was calculated using the year of T2DM onset or the registration date of T2DM in the National Diabetes Register (94\%), or the duration of antidiabetic medications in the National Prescribed Drug Register (6\%).

In addition, we also used duration of antidiabetic medications, including insulin, metformin, and sulphonylurea (SU) as documented in the National Prescribed Drug Register up to 8.5 years prior to the date of $\mathrm{PCa}$ diagnosis (July 2005 - December 2016). As the Swedish drug reimbursement system is based on records of patients' visiting to the pharmacies every 3 months, the 8.5-year period in the National Prescribe Drug Register was divided into 34 sub-periods, which were shown as 34 filled prescription records in the dataset of the study. Each filled prescription record equates to 3 months' antidiabetic medication. Men with at least two filled prescription records of the same antidiabetic medication were assumed to be taking that antidiabetic drug as a treatment of T2DM. The duration of an antidiabetic drug was defined by the number of the corresponding records found in the National Prescribed Drug Register.

Use of metformin was divided into high-dose and lowdose groups with a cut-off at $1 \mathrm{~g}$ of metformin per day. 
We categorized duration into 3 groups: (i) $\geq 0.5$ year $-<$ 3 years, (ii) $\geq 3$ year $-<5$ years, and (iii) 5 year $-\leq 8.5$ years. We calculated duration of insulin, metformin, and SU separately, even if some men received more than one antidiabetic drug. For example, if a man took high-dose metformin and insulin at the same time, he contributed time to the duration of both high-dose metformin and insulin.

\section{Outcome}

The primary outcome of the study was diagnosis of PCa, and we also obtained information on PCa risk categories from the NPCR. According to the modified version of the National Comprehensive Cancer Network (NCCN) guideline, men with $\mathrm{PCa}$ can be categorized into five risk categories: i) low-risk: T1 or T2a stage, PSA $<10 \mathrm{ng} / \mathrm{mL}$ and Gleason score 6; ii) intermediate-risk: T2b or T2c stage, $10 \mathrm{ng} / \mathrm{mL}, \mathrm{PSA}<20 \mathrm{ng} / \mathrm{mL}$, or Gleason score 7; iii) high-risk: T3a or T4 stage, PSA $\geq 20 \mathrm{ng} / \mathrm{mL}$, or Gleason score $\geq 8$; iv) regional metastases any $\mathrm{T}, \mathrm{N} 1$ and $\mathrm{M} 0$ stage; v) distant metastases, any $\mathrm{T}$ or $\mathrm{N}$ and $\mathrm{M} 1$ stage [22]. In the main analysis, we included men with highrisk, regional metastases, and distant metastases into the high-risk category group to increase the power. We also conducted a subgroup analysis for each category.

\section{Statistical analysis}

Conditional logistic regression was used to calculate odds ratios (OR) and 95\% confidence intervals (CI) for PCa risk. Models were adjusted for education levels (high, middle and low), civil status (married, not married, widowed and divorced), CCI and age at the year of PCa diagnosis.

All data management was performed with STATA 15.1. The study has been approved by The Research Ethics Board at Uppsala University, Sweden.

\section{Results}

31,415 men with PCa and 154,812 PCa-free men were included in the study. Table 1 shows their baseline characteristics. Of the men with PCa, 4186 (13\%) had T2DM, whereas among the controls 24,965 (16\%) had T2DM. Age, education level, civil status and CCI were similar for cases and controls (Table 1). PCa men with T2DM were more likely to be diagnosed with advanced PCa or metastatic disease and had higher PSA and Gleason grade group 4 \& 5 compared with PCa men without T2DM, as shown in Table 2.

\section{The association of duration of T2DM and antidiabetic medications with $\mathrm{PCa}$ risk}

Overall, a decreased risk of PCa was observed for men with T2DM (OR: 0.81, 95\% CI: 0.78-0.84), as compared to men without T2DM.
Table 1 Characteristics of men in PCBaSe 4.1 diagnosed with prostate cancer between 2014 and $2016(n=31,415)$ and their matched controls $(n=154,812)$

\begin{tabular}{|c|c|c|c|c|}
\hline & \multicolumn{2}{|c|}{ Controls, $\boldsymbol{N}=154,812$} & \multicolumn{2}{|c|}{ Cases, $\boldsymbol{N}=31,415$} \\
\hline & $N$ & $\%$ & $N$ & $\%$ \\
\hline \multicolumn{5}{|c|}{ Age (year), $n(\%)$} \\
\hline$<50$ & 1617 & 1.0 & 326 & 1.0 \\
\hline 50-59 & 17,806 & 11.5 & 3625 & 11.5 \\
\hline 60-69 & 61,287 & 39.6 & 12,514 & 39.8 \\
\hline $70-79$ & 54,062 & 34.9 & 10,900 & 34.7 \\
\hline $80+$ & 20,040 & 12.9 & 4050 & 12.9 \\
\hline \multicolumn{5}{|c|}{ Education level, $n$ (\%) } \\
\hline Low & 48,882 & 31.6 & 9311 & 29.6 \\
\hline Middle & 79,904 & 51.6 & 16,553 & 52.7 \\
\hline High & 24,159 & 15.6 & 5348 & 17.0 \\
\hline Missing & 18,67 & 1.2 & 203 & 0.6 \\
\hline \multicolumn{5}{|c|}{ Civil status, $n$ (\%) } \\
\hline Married & 92,576 & 59.8 & 20,122 & 64.1 \\
\hline Not married & 24,431 & 15.8 & 4120 & 13.1 \\
\hline Divorced & 26,647 & 17.2 & 4946 & 15.7 \\
\hline Widower & 11,151 & 7.2 & 2216 & 7.1 \\
\hline Missing & 7 & 0.0 & 11 & 0.0 \\
\hline \multicolumn{5}{|l|}{$\mathrm{CCl}, n(\%)$} \\
\hline 0 & 113,602 & 73.4 & 23,616 & 75.2 \\
\hline 1 & 20,102 & 13.0 & 3734 & 11.9 \\
\hline 2 & 12,032 & 7.8 & 2501 & 8.0 \\
\hline $3+$ & 9076 & 5.9 & 1562 & 5.0 \\
\hline
\end{tabular}

Numbers may not add up to $100 \%$ due to rounding

Abbreviations: $\mathrm{N}$ number, $\mathrm{CCl}$ Charlson Comorbidity Index

There was a consistent reduction of PCa risk over all durations of T2DM, except for men who were diagnosed of T2DM less than 1 year prior to PCa diagnosis. We found a $19 \%$ reduction in risk of PCa among men with T2DM for $\geq 1$ year and $<5$ years and a $27 \%$ reduction in risk of $\mathrm{PCa}$ for men with pre-existing T2DM for at least 20 years as compared to men without T2DM (Table 3). Men on insulin, high-and low-dose metformin, and SU showed a persistently decreased risk of PCa over all durations (Table 3).

The association of duration of T2DM and antidiabetic medications with $\mathrm{PCa}$ risk categories

There was a decreased risk of low- and intermediaterisk $\mathrm{PCa}$ for men with $\mathrm{T} 2 \mathrm{DM}$, as compared to men without T2DM (Table 4). The decreased risk persisted over time, with the largest reduction found for men whose duration of T2DM was 10-20 years in the lowrisk category and over 20 years in intermediate-risk category. However, no association was found for the high-risk category. 
Table 2 Characteristics of men in PCBaSe 4.1 diagnosed with prostate cancer between 2014 by T2DM status

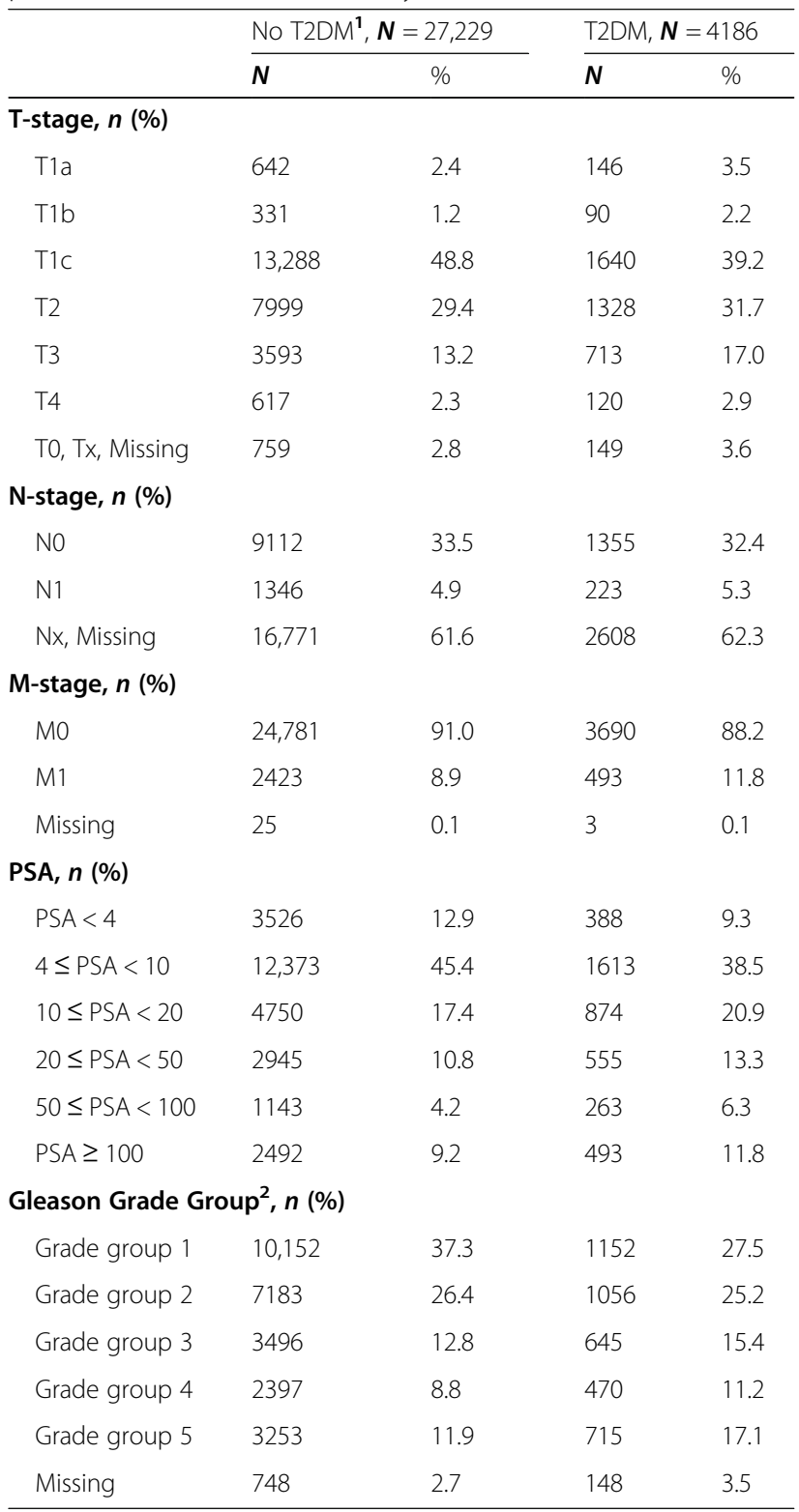

Numbers may not add up to $100 \%$ due to rounding

${ }^{2}$ Gleason grade group $1=$ Gleason Score $\leq 6$, Grade group $2=$ Gleason Score $3+4=7$, Grade group $3=$ Gleason Score $4+3=7$, Grade group $4=$ Gleason Score $4+4,3+5,5+3=8$, Grade group $5=$ Gleason Score 9 and 10 Abbreviations: $N$ number, T2DM type 2 diabetes mellitus, PSA Prostate-Specific Antigen

With respect to duration of antidiabetic medications, the reduction in PCa risk was again clearest for low and intermediate-risk PCa. For those taking insulin, there was a decreased risk of low-risk PCa (OR: 0.42, 95\% CI: $0.31-0.56$ ) at $0.5-3$ years (Table 4). A similar association was seen for men taking high- and low-dose metformin and SU. For the intermediate-risk PCa category, there was a decreased risk with all durations of different antidiabetic medications. In contrast, no association was observed in high-risk PCa category (Table 4). No clear associations were observed inthe subgroup analysis, inwhich the high-risk category was further divided into: high-risk, regional metastases, and distant metastases (Table 5).

\section{Discussion}

In this nationwide, population-based case-control study, we observed that men with T2DM had a decreased risk of PCa for any duration of T2DM, as well as any exposure time to all types of antidiabetic medication. The reduction in risk was strongest for low- and intermediaterisk $\mathrm{PCa}$, whereas there was no decrease for high-risk PCa.

\section{Duration of T2DM medication}

We found a consistent reduction of PCa risk over all durations of T2DM, which supports previous studies [4, 23-25]. This study provides new observations regarding duration of antidiabetic drugs, including metformin, insulin and SU. The results demonstrate a persistently decreased risk of $\mathrm{PCa}$ for all anti-diabetic medications and durations. One possible explanation for this observation is that metformin and insulin are thought to reduce the activity of mTOR, which blocks progression of the cell cycle and cancer growth [26, 27]. For example, Pircher et al. conducted a study exploring antidiabetic drugs that influence molecular mechanisms in prostate cancer and showed that insulin use significantly decreased active mTOR in cancer tissue [26]. In addition, they found an AMPK and AKT independent regulation of the mTOR pathway, as there were no differences in pAKT levels among treatment groups (insulin and metformin groups) [26]. Hence, medication that can attenuate mTOR activity with subsequent blockade of cell cycle progression, can potentially also block the progression of the prostate cell cycle and cancer growth [28]. However, some observational studies have shown no protective effect of metformin and insulin on PCa risk [14, 29-31]. These studies did not take selection bias and confounding into account. Studies examining the impact of SU on PCa risk have provided inconsistent results [11,32, 33]. No previous study has examined SU separately from other antidiabetic drugs or examined the impact of its duration on PCa risk, as we have here.

\section{Risk categories of PCa}

We found a consistently stronger inverse association of duration of T2DM and antidiabetic medications with risk of low and intermediate-risk PCa. This association was not observed for high-risk PCa, regional and distant metastatic PCa. These results are consistent with previous large population-based studies [23, 33, 34], which concluded that neither T2DM nor antidiabetic medications were associated with a reduction in risk of aggressive PCa. Conversely, some 
Table 3 Odds ratios and 95\% Cls for risk of prostate cancer according to type 2 diabetes mellitus (T2DM) status and T2DM medications

\begin{tabular}{|c|c|c|c|c|c|c|}
\hline \multirow{2}{*}{$\begin{array}{l}\text { Dependent } \\
\text { variables }\end{array}$} & \multirow{2}{*}{$\begin{array}{l}\text { Controls } \\
\boldsymbol{N}=154,812\end{array}$} & \multirow{2}{*}{$\begin{array}{l}\text { Cases } \\
\mathbf{N}=31,415\end{array}$} & \multicolumn{2}{|c|}{ Model $1^{1}$} & \multicolumn{2}{|c|}{ Model $2^{2}$} \\
\hline & & & $\overline{\mathrm{OR}}$ & $95 \% \mathrm{Cl}$ & $\overline{\mathrm{OR}}$ & $95 \% \mathrm{Cl}$ \\
\hline \multicolumn{7}{|l|}{ T2DM } \\
\hline no DM & 129,847 & 27,229 & Ref & & Ref & \\
\hline T2DM & 24,965 & 4186 & 0.80 & $(0.77-0.83)$ & 0.81 & $(0.78-0.84)$ \\
\hline \multicolumn{7}{|c|}{ Duration of T2DM (years) } \\
\hline no DM & 129,847 & 27,229 & Ref & & Ref & \\
\hline$<1$ & 1306 & 307 & 1.12 & $(0.99-1.27)$ & 1.15 & $(1.01-1.30)$ \\
\hline $1-<5$ & 5983 & 990 & 0.79 & $(0.74-0.84)$ & 0.81 & $(0.75-0.86)$ \\
\hline $5-<10$ & 6862 & 1144 & 0.79 & $(0.74-0.85)$ & 0.81 & $(0.76-0.86)$ \\
\hline $10-<20$ & 7724 & 1269 & 0.78 & $(0.73-0.83)$ & 0.79 & $(0.75-0.84)$ \\
\hline 20 & 3090 & 476 & 0.73 & $(0.66-0.81)$ & 0.73 & $(0.67-0.81)$ \\
\hline \multicolumn{7}{|c|}{ Duration of Insulin (years) } \\
\hline no DM & 129,847 & 27,229 & Ref & & Ref & \\
\hline $0.5-<3$ & 2370 & 335 & 0.67 & $(0.59-0.75)$ & 0.68 & $(0.60-0.76)$ \\
\hline $3-<5$ & 1498 & 208 & 0.67 & $(0.58-0.77)$ & 0.69 & $(0.60-0.80)$ \\
\hline 5 & 4323 & 645 & 0.71 & $(0.65-0.77)$ & 0.72 & $(0.66-0.79)$ \\
\hline Missing & 16,774 & 2998 & & & & \\
\hline \multicolumn{7}{|c|}{ Duration of high-dose Metformin (years) } \\
\hline no DM & 129,847 & 27,229 & Ref & & Ref & \\
\hline $0.5-<3$ & 6339 & 1010 & 0.76 & $(0.71-0.82)$ & 0.77 & $(0.72-0.83)$ \\
\hline $3-<5$ & 2450 & 410 & 0.80 & $(0.72-0.90)$ & 0.82 & $(0.74-0.91)$ \\
\hline 5 & 2117 & 376 & 0.86 & $(0.77-0.96)$ & 0.87 & $(0.78-0.98)$ \\
\hline Missing & 14,059 & 2390 & & & & \\
\hline \multicolumn{7}{|c|}{ Duration of low-dose Metformin (years) } \\
\hline no DM & 129,847 & 27,229 & Ref & & Ref & \\
\hline $0.5-<3$ & 10,069 & 1588 & 0.75 & $(0.71-0.80)$ & 0.77 & $(0.72-0.81)$ \\
\hline $3-<5$ & 3926 & 663 & 0.80 & $(0.74-0.87)$ & 0.82 & $(0.75-0.89)$ \\
\hline 5 & 1918 & 343 & 0.85 & $(0.76-0.96)$ & 0.87 & $(0.77-0.97)$ \\
\hline Missing & 9052 & 1592 & & & & \\
\hline \multicolumn{7}{|c|}{ Duration of SU (years) } \\
\hline no DM & 129,847 & 27,229 & Ref & & Ref & \\
\hline $0.5-<3$ & 2604 & 369 & 0.68 & $(0.61-0.76)$ & 0.68 & $(0.61-0.76)$ \\
\hline $3-<5$ & 1402 & 216 & 0.72 & $(0.62-0.83)$ & 0.72 & $(0.62-0.83)$ \\
\hline 5 & 1903 & 293 & 0.74 & $(0.66-0.84)$ & 0.76 & $(0.67-0.86)$ \\
\hline Missing & 19,056 & 3308 & & & & \\
\hline
\end{tabular}

${ }^{1}$ Crude; $^{2}$ adjusted for $\mathrm{CCl}$, education level, civil status and the age at year of PCa onset

Abbreviations: OR odds ratio, 95\% Cl 95\% confidence interval, PCa prostate cancer, T2DM type 2 diabetes mellitus, SU sulfonylurea

studies [35-38] have found that T2DM is associated with increased risk of high-grade PCa. The biological mechanism behind this remains unclear [14].

It is essential to consider detection bias when evaluating the association of T2DM and antidiabetic treatments with different risk categories of PCa. Early detection of PCa depends on PSA testing and subsequent biopsy of the prostate. PSA levels have been shown to be lower in T2DM patients than in non-diabetic men [39]. Therefore, PSA is less sensitive to detect early-stage PCa in men with T2DM. Prostate size among PCa men with T2DM has been reported to be larger than in men without T2DM, which may affect biopsy results [40]. A larger prostate may dilute the cancer cells, which may 
Table 4 Association of T2DM medications with risk categories of prostate cancer 1

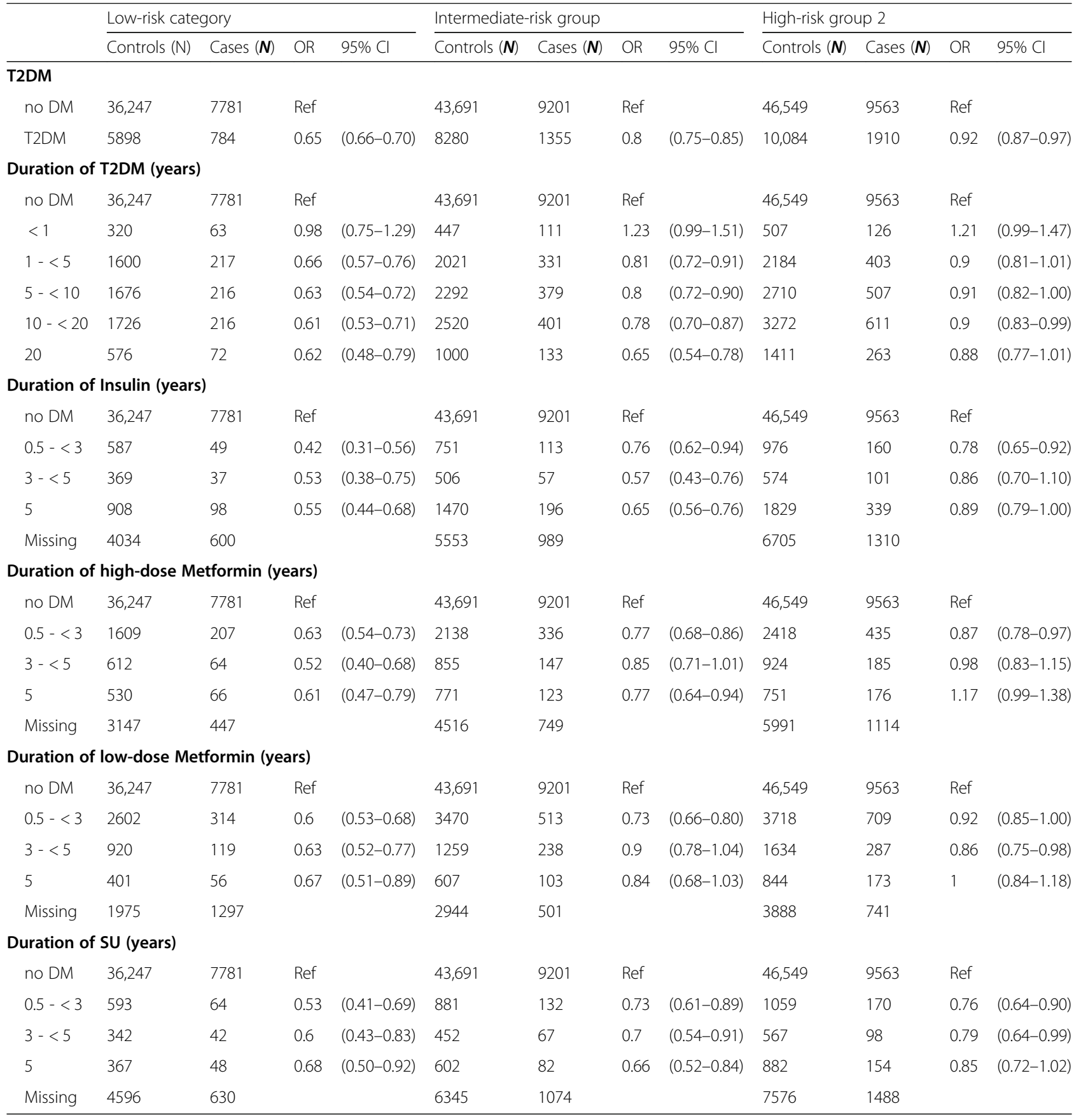

1 The results were adjusted for $\mathrm{CCl}$, education level, civil status and the age at year of PCa onset

2 We combined high risk, reginal metastases, and distant metastases into high-risk category group

cause a decrease in the probability of the detection of small indolent cancers in the low-risk category group using biopsy [39]. These two observations may affect PCa detection at an early stage, which may partially explain the decreased risk of low-risk PCa among men with T2DM. Men with T2DM who developed into PCa are therefore more likely to be diagnosed at a more advanced stage.

\section{Strengths/limitations}

The strength of this study is the use of data from a national-wide cohort in Sweden, which has been linked to other national high-quality registers and demographic databases including the Longitudinal integrated database for health insurance and labour market studies, the National Diabetes Register and the National Prescribed Drug Register. Since previous PCBaSe studies were performed, there 
Table 5 Association of T2DM and antidiabetic medications with high-risk, regional metastases and distant metastases of prostate cancer 1

\begin{tabular}{|c|c|c|c|c|c|c|c|c|c|c|c|c|}
\hline & \multicolumn{4}{|l|}{ High risk 2} & \multicolumn{4}{|c|}{ Regional metastases } & \multicolumn{4}{|c|}{ Distant metastases } \\
\hline & Controls $(\boldsymbol{N})$ & Cases $(\boldsymbol{N})$ & OR & $95 \% \mathrm{Cl}$ & Controls $(\boldsymbol{N})$ & Cases $(\boldsymbol{N})$ & OR & $95 \% \mathrm{Cl}$ & Controls $(\boldsymbol{N})$ & Cases $(\boldsymbol{N})$ & OR & $95 \% \mathrm{Cl}$ \\
\hline \multicolumn{13}{|l|}{ T2DM } \\
\hline no DM & 24,746 & 5081 & Ref & & 6772 & 1398 & Ref & & 15,031 & 3084 & Ref & \\
\hline T2DM & 5333 & 1011 & 0.93 & $(0.87-1.00)$ & 1519 & 282 & 0.9 & $(0.78-1.04)$ & 3232 & 617 & 0.91 & $(0.82-1.00)$ \\
\hline \multicolumn{13}{|c|}{ Duration of T2DM (years) } \\
\hline no DM & 24,746 & 5081 & Ref & & 6772 & 1398 & Ref & & 15,031 & 3084 & Ref & \\
\hline$<1$ & 257 & 67 & 1.28 & $(0.97-1.68)$ & 92 & 15 & 0.76 & $(0.43-1.35)$ & 158 & 44 & 1.33 & $(0.95-1.87)$ \\
\hline $1-<5$ & 1122 & 224 & 0.99 & $(0.85-1.14)$ & 350 & 62 & 0.87 & $(0.66-1.15)$ & 712 & 117 & 0.8 & $(0.65-0.97)$ \\
\hline $5-<10$ & 1453 & 281 & 0.95 & $(0.83-1.08)$ & 396 & 68 & 0.84 & $(0.64-1.09)$ & 816 & 158 & 0.87 & $(0.73-1.04)$ \\
\hline $10-<20$ & 1727 & 316 & 0.9 & $(0.80-1.02)$ & 467 & 94 & 0.97 & $(0.77-1.22)$ & 1078 & 201 & 0.89 & $(0.76-1.04)$ \\
\hline 20 & 774 & 123 & 0.77 & $(0.63-0.94)$ & 214 & 43 & 0.96 & $(0.69-1.35)$ & 423 & 97 & 1.06 & $(0.84-1.32)$ \\
\hline
\end{tabular}

Duration of Insulin (years)

$\begin{array}{lllllllllllll}\text { no DM } & 24,746 & 5081 & \text { Ref } & & 6772 & 1398 & \text { Ref } & 15,031 & 3084 & \text { Ref } \\ 0.5-<3 & 509 & 80 & 0.77 & (0.60-0.98) & 150 & 16 & 0.52 & (0.31-0.88) & 317 & 64 & 0.9 & (0.68-1.19) \\ 3-<5 & 291 & 46 & 0.85 & (0.63-1.16) & 86 & 17 & 0.97 & (0.57-1.65) & 197 & 35 & 0.83 & (0.58-1.20) \\ 5 & 971 & 169 & 0.86 & (0.72-1.01) & 270 & 50 & 0.88 & (0.64-1.21) & 588 & 120 & 0.96 & (0.78-1.18) \\ \text { Missing } & 3562 & 713 & & & 1013 & 199 & & & 2130 & 398 & & \end{array}$

\section{Duration of high-dose Metformin (years)}

$\begin{array}{lllllllllllll}\text { no DM } & 24,746 & 5081 & \text { Ref } & & 6772 & 1398 & \text { Ref } & & 15,031 & 3084 & \text { Ref } \\ 0.5-<3 & 1290 & 235 & 0.89 & (0.77-1.03) & 367 & 66 & 0.87 & (0.66-1.15) & 761 & 134 & 0.84 & (0.69-1.02) \\ 3-<5 & 508 & 97 & 0.96 & (0.77-1.20) & 125 & 33 & 1.23 & (0.82-1.83) & 291 & 55 & 0.89 & (0.67-1.20) \\ 5 & 408 & 95 & 1.19 & (0.94-1.50) & 112 & 23 & 0.96 & (0.61-1.52) & 231 & 58 & 1.25 & (0.93-1.68) \\ \text { Missing } & 3127 & 584 & & & 915 & 160 & & & 1949 & 370 & & \end{array}$

\section{Duration of low-dose Metformin (years)}

\begin{tabular}{|c|c|c|c|c|c|c|c|c|c|c|c|c|}
\hline no DM & 24,746 & 5081 & Ref & & 6772 & 1398 & Ref & & 15,031 & 3084 & Ref & \\
\hline $0.5-<3$ & 1966 & 385 & 0.97 & $(0.86-1.09)$ & 552 & 101 & 0.89 & $(0.71-1.12)$ & 1200 & 223 & 0.86 & $(0.74-1.00)$ \\
\hline $3-<5$ & 891 & 152 & 0.85 & $(0.72-1.02)$ & 228 & 48 & 1 & $(0.73-1.38)$ & 515 & 87 & 0.81 & $(0.64-1.02)$ \\
\hline 5 & 428 & 86 & 0.97 & $(0.76-1.23)$ & 124 & 33 & 1.44 & $(0.97-2.15)$ & 292 & 54 & 0.87 & $(0.65-1.17)$ \\
\hline Missing & 2048 & 388 & & & 615 & 100 & & & 1225 & 253 & & \\
\hline \multicolumn{13}{|c|}{ uration of SU (years) } \\
\hline no DM & 24,746 & 5081 & Ref & & 6772 & 1398 & Ref & & 15,031 & 3084 & Ref & \\
\hline $0.5-<3$ & 559 & 81 & 0.7 & $(0.55-0.88)$ & 151 & 29 & 0.89 & $(0.58-1.36)$ & 349 & 60 & 0.83 & $(0.62-1.09)$ \\
\hline $3-<5$ & 302 & 54 & 0.85 & $(0.63-1.15)$ & 78 & 15 & 0.95 & $(0.53-1.70)$ & 187 & 29 & 0.65 & $(0.43-0.98)$ \\
\hline 5 & 469 & 69 & 0.74 & $(0.57-0.96)$ & 128 & 22 & 0.81 & $(0.51-1.28)$ & 285 & 63 & 1.07 & $(0.81-1.42)$ \\
\hline Missing & 4003 & 807 & & & 1162 & 216 & & & 2411 & 465 & & \\
\hline
\end{tabular}

1 The results were adjusted for $\mathrm{CCl}$, education level, civil status and the age at year of PCa onset

2 Cases in "high risk" only refer to PCa men at T3a or T4 stage, whose PSA $\geq 20 \mathrm{ng} / \mathrm{ml}$ or Gleason Score $\geq 8$, without regional metastases and distant metastases

has been a substantial improvement in the completeness of the National Diabetes Register [41], which make the data in this study more representative. We also included information from the Prescribed Drug Registry, which comprises all out-patients filled prescription data since July 2005 [41]. We were also able to investigate the association of different anti-diabetic medications including high-dose and low-dose metformin with PCa risk using detailed prescription data from the National Prescribed Drug Register. Thirdly, our study had a longer follow-up (8.5 years) than other studies where median follow-up was 5-7 years $[14,29,42]$. A limitation of our study is that there was insufficient power to investigate associations of exposure times to antidiabetic medications with low-risk/ 
intermediate-risk/ high-risk $\mathrm{PCa}$ given the smaller number of men with $\mathrm{PCa}$ in these specific risk categories. Secondly, our study may be prone to residual confounding (e.g., family history of T2DM and PCa), although we obtained detailed information of participants' socioeconomic status from the Longitudinal integrated database for health insurance and labour market studies database. Thirdly, approximately $6 \%$ of participants had missing data on the date of T2DM diagnosis and registration in the National Diabetes Register registry. We used duration of antidiabetic medications in the National Prescribed Drug Register to replace these missing values, which may result in a shorter interval between T2DM diagnosis and PCa diagnosis.

\section{Conclusion}

There was a persistent decreased risk of PCa across all anti-diabetic medications studied and across all durations of T2DM. This association was strongest for risk of lowand intermediate risk $\mathrm{PCa}$ and not observed for high-risk PCa. Given the prevalence of T2DM worldwide, it is important to note that T2DM and its medication may protect some men from $\mathrm{PCa}$, though not necessarily from developing high risk disease. However, the interplay between T2DM and PCa warrants further study.

\section{Abbreviations}

PCa: Prostate cancer; PSA: Prostate-Specific Antigen; T2DM: Type 2 diabetes mellitus; SU: Sulfonylurea; CCl: Charlson Comorbidity Index; OR: Odds ratio; 95\% Cl: 95\% confidence interval; PCBaSe: Prostate Cancer data Base Sweden

\section{Acknowledgements}

This project was made possible by the continuous work of the National Prostate Cancer Register of Sweden (the National Prostate Cancer Register) steering group: Pär Stattin (chair), Ingela Franck Lissbrant (deputy chair), Johan Styrke, Camilla Thellenberg Karlsson, Lennart Åström, Stefan Carlsson, Marie Hjälm-Eriksson, David Robinson, Mats Andén, Ola Bratt, Magnus Törnblom, Jonas Hugosson, Maria Nyberg, Olof Akre, Per Fransson, Eva Johansson, Gert Malmberg, Fredrik Sandin, and Karin Hellström.

\section{Authors' contributions}

This research was mainly designed and coordinated by EL, DC, HG and MVH. $J A, P S$ and BZ participated in research coordination. EL carried out, analyzed and interpreted the data with $\mathrm{HG}, \mathrm{DC}$ and $\mathrm{MVH}$. JA, PS and BZ made substantial contribution to the collection and interpretation of data. EL drafted the manuscript. DC, MVH, HG, JA, PS and BZ have substantively revised it. All authors read and approved the final manuscript and agreed to be personally accountable for the author's own contributions and to ensure the accuracy and integrity of the manuscript.

\section{Funding}

This work was supported by The Swedish Research Council 2017-00847, The Swedish Cancer Society 160700 and The Stockholm Cancer Society.

\section{Availability of data and materials}

The data that support the findings of this study are available from PCBaSe Sweden, but restrictions apply to the availability of these data, which were used under license for the current study, and so are not publicly available. Data are however available from the authors upon reasonable request and with permission of PCBaSe Sweden.
Ethics approval and consent to participate

The study has been approved by The Research Ethics Board at Uppsala University, Sweden.

\section{Consent for publication}

Not applicable.

\section{Competing interests}

Hans Garmo, Mieke Van Hemelrijck, Jan Adolfsson, Pär Stattin and Björn Zethelius do not have competing interests. Björn Zethelius is employed at the Swedish Medical Products Agency, SE-751 03 Uppsala, Sweden. The views expressed in this paper are the personal views of the authors and not necessarily the views of the Swedish government agency.

\section{Author details}

'School of Cancer and Pharmaceutical Sciences, Translational Oncology and Urology Research (TOUR), King's College London, London, UK. ²Department of Clinical Science, Intervention and Technology, Karolinska Institute, Stockholm, Sweden. ${ }^{3}$ Department of Surgical Sciences, Uppsala University, Uppsala, Sweden. ${ }^{4}$ Department of Public Health/Geriatrics, Uppsala University, Uppsala, Sweden.

Received: 18 November 2019 Accepted: 3 June 2020

Published online: 15 June 2020

\section{References}

1. Crawley D, Garmo H, Rudman S, Stattin P, Zethelius B, Armes J, Holmberg L, Adolfsson J, Van Hemelrijck M. Does a prostate cancer diagnosis affect management of pre-existing diabetes? Results from PCBaSe Sweden: a nationwide cohort study. BMJ Open. 2018;8(3):e020787.

2. Tsilidis KK, Allen NE, Appleby PN, Rohrmann S, Nothlings U, Arriola L, Gunter MJ, Chajes V, Rinaldi S, Romieu I, et al. Diabetes mellitus and risk of prostate cancer in the European prospective investigation into Cancer and nutrition. Int J Cancer. 2015;136(2):372-81.

3. Lawrence YR, Morag O, Benderly M, Boyko V, Novikov I, Dicker AP, Goldbourt U, Behar S, Barchana M, Wolf I. Association between metabolic syndrome, diabetes mellitus and prostate cancer risk. Prostate Cancer Prostatic Dis. 2013;16(2):181-6.

4. Fall K, Garmo H, Gudbjornsdottir S, Stattin P, Zethelius B. Diabetes mellitus and prostate cancer risk; a nationwide case-control study within PCBaSe Sweden. Cancer Epidemiol Biomarkers Prevent. 2013;22(6):1102-9.

5. Moses KA, Utuama OA, Goodman M, Issa MM. The association of diabetes and positive prostate biopsy in a US veteran population. Prostate Cancer Prostatic Dis. 2012;15(1):70-4.

6. Dankner R, Boffetta P, Balicer RD, Boker LK, Sadeh M, Berlin A, Olmer L, Goldfracht M, Freedman LS. Time-dependent risk of Cancer after a diabetes diagnosis in a cohort of 2.3 million adults. Am J Epidemiol. 2016;183(12): 1098-106.

7. Magliano DJ, Davis WA, Shaw JE, Bruce DG, Davis TM. Incidence and predictors of all-cause and site-specific cancer in type 2 diabetes: the Fremantle diabetes study. Eur J Endocrinol. 2012;167(4):589-99.

8. Lai GY, Park $Y$, Hartge P, Hollenbeck AR, Freedman ND. The association between self-reported diabetes and cancer incidence in the NIH-AARP diet and health study. J Clin Endocrinol Metab. 2013;98(3):E497-502.

9. Murtola TJ, Tammela TL, Lahtela J, Auvinen A. Antidiabetic medication and prostate cancer risk: a population-based case-control study. Am J Epidemiol. 2008;168(8):925-31.

10. Preston MA, Riis AH, Ehrenstein V, Breau RH, Batista JL, Olumi AF, Mucci LA, Adami HO, Sorensen HT. Metformin use and prostate cancer risk. Eur Urol. 2014;66(6):1012-20.

11. Tseng $\mathrm{CH}$. Metformin significantly reduces incident prostate cancer risk in Taiwanese men with type 2 diabetes mellitus. Eur J Cancer. 2014;50(16): 2831-7.

12. Wright JL, Stanford JL. Metformin use and prostate cancer in Caucasian men: results from a population-based case-control study. Cancer Causes Control. 2009;20(9):1617-22.

13. Carstensen B, Witte DR, Friis S. Cancer occurrence in Danish diabetic patients: duration and insulin effects. Diabetologia. 2012;55(4):948-58.

14. Margel D, Urbach D, Lipscombe LL, Bell CM, Kulkarni G, Austin PC, Fleshner N. Association between metformin use and risk of prostate cancer and its grade. J Natl Cancer Inst. 2013;105(15):1123-31. 
15. Chen YB, Chen Q, Wang Z, Zhou J. Insulin therapy and risk of prostate cancer: a systematic review and meta-analysis of observational studies. PLoS One. 2013;8(11):e81594.

16. Karlstad O, Starup-Linde J, Vestergaard P, Hjellvik V, Bazelier MT, Schmidt MK, Andersen M, Auvinen A, Haukka J, Furu K, et al. Use of insulin and insulin analogs and risk of cancer - systematic review and meta-analysis of observational studies. Curr Drug Saf. 2013;8(5):333-48.

17. Tsilidis KK, Capothanassi D, Allen NE, Rizos EC, Lopez DS, van Veldhoven K, Sacerdote C, Ashby D, Vineis P, Tzoulaki I, et al. Metformin does not affect cancer risk: a cohort study in the U.K. clinical practice research Datalink analyzed like an intention-to-treat trial. Diabetes Care. 2014;37(9):2522-32.

18. Van Hemelrijck M, Wigertz A, Sandin F, Garmo H, Hellstrom K, Fransson P, Widmark A, Lambe M, Adolfsson J, Varenhorst E, et al. Cohort profile: the National Prostate Cancer Register of Sweden and prostate Cancer data base Sweden 2.0. Int J Epidemiol. 2013;42(4):956-67.

19. Van Hemelrijck M, Folkvaljon Y, Adolfsson J, Akre O, Holmberg L, Garmo H, Stattin P. Causes of death in men with localized prostate cancer: a nationwide, population-based study. BJU Int. 2016;117(3):507-14.

20. Crawley D, Garmo H, Rudman S, Stattin P, Haggstrom C, Zethelius B, Holmberg L, Adolfsson J, Van Hemelrijck M. Association between duration and type of androgen deprivation therapy and risk of diabetes in men with prostate cancer. Int J Cancer. 2016;139(12):2698-704.

21. Van Hemelrijck M, Garmo H, Wigertz A, Nilsson P, Stattin P. Cohort profile update: the National Prostate Cancer Register of Sweden and prostate Cancer data base--a refined prostate cancer trajectory. Int J Epidemiol. 2016; 45(1):73-82

22. Mohler JL, Antonarakis ES, Armstrong AJ, D'Amico AV, Davis BJ, Dorff T, Eastham JA, Enke CA, Farrington TA, Higano CS, et al. Prostate Cancer, version 2.2019, NCCN clinical practice guidelines in oncology. J Natl Comprehen Cancer Netw. 2019;17(5):479-505.

23. Bansal D, Bhansali A, Kapil G, Undela K, Tiwari P. Type 2 diabetes and risk of prostate cancer: a meta-analysis of observational studies. Prostate Cancer Prostatic Dis. 2013;16(2):151-8 s151.

24. Kasper JS, Giovannucci E. A meta-analysis of diabetes mellitus and the risk of prostate cancer. Cancer Epidemiol Biomarkers Prevent. 2006; 15(11):2056-62.

25. Hense HW, Kajuter H, Wellmann J, Batzler WU. Cancer incidence in type 2 diabetes patients - first results from a feasibility study of the D2C cohort. Diabetol Metab Syndrome. 2011;3(1):15.

26. Pircher A, Zieher M, Eigentler A, Pichler R, Schafer G, Fritz J, Puhr M, Steiner E, Horninger W, Klocker $\mathrm{H}$, et al. Antidiabetic drugs influence molecular mechanisms in prostate cancer. Cancer Biol Ther. 2018;19(12):1153-61.

27. Tam WL, Weinberg RA. The epigenetics of epithelial-mesenchymal plasticity in cancer. Nat Med. 2013;19(11):1438-49.

28. Zakikhani M, Dowling RJO, Sonenberg N, Pollak MN. The effects of adiponectin and metformin on prostate and colon neoplasia involve activation of AMP-activated protein kinase. Cancer Prevent Res. 2008; 1(5):369-75

29. Nordstrom T, Clements M, Karlsson R, Adolfsson J, Gronberg H. The risk of prostate cancer for men on aspirin, statin or antidiabetic medications. Europ J Cancer. 2015;51(6):725-33.

30. Margel D, Urbach DR, Lipscombe LL, Bell CM, Kulkarni G, Austin PC, Fleshner N. Metformin use and all-cause and prostate cancer-specific mortality among men with diabetes. J Clin Oncol. 2013;31(25):3069-75.

31. Zhang $P$, Li H, Tan X, Chen L, Wang S. Association of metformin use with cancer incidence and mortality: a meta-analysis. Cancer Epidemiol. 2013; 37(3):207-18.

32. Gonzalez-Perez A, Garcia Rodriguez LA. Prostate cancer risk among men with diabetes mellitus (Spain). Cancer Causes Control. 2005;16(9):1055-8.

33. Haring A, Murtola TJ, Talala K, Taari K, Tammela TL, Auvinen A. Antidiabetic drug use and prostate cancer risk in the Finnish randomized study of screening for prostate Cancer. Scand J Urol. 2017;51(1):5-12.

34. Raval AD, Mattes MD, Madhavan S, Pan X, Wei W, Sambamoorthi U. Association between metformin use and Cancer stage at diagnosis among elderly Medicare beneficiaries with preexisting type 2 diabetes mellitus and incident prostate Cancer. J Diab Res. 2016;2016:2656814.

35. Hong SK, Oh JJ, Byun SS, Hwang SI, Lee HJ, Choe G, Lee SE. Impact of diabetes mellitus on the detection of prostate cancer via contemporary multi (>/= 12)-core prostate biopsy. Prostate. 2012;72(1):51-7.

36. Li Q, Kuriyama S, Kakizaki M, Yan H, Sone T, Nagai M, Sugawara Y, OhmoriMatsuda K, Hozawa A, Nishino Y, et al. History of diabetes mellitus and the risk of prostate cancer: the Ohsaki cohort study. Cancer Causes Control. 2010;21(7):1025-32.

37. Moreira DM, Anderson T, Gerber L, Thomas JA, Banez LL, McKeever MG, Hoyo C, Grant D, Jayachandran J, Freedland SJ. The association of diabetes mellitus and high-grade prostate cancer in a multiethnic biopsy series. Cancer Causes Control. 2011;22(7):977-83.

38. Tseng $\mathrm{CH}$. Diabetes and risk of prostate cancer: a study using the National Health Insurance. Diabetes Care. 2011;34(3):616-21.

39. Pierce BL. Why are diabetics at reduced risk for prostate cancer? A review of the epidemiologic evidence. Urol Oncol. 2012;30(5):735-43.

40. Kim WT, Yun SJ, Choi YD, Kim GY, Moon SK, Choi YH, Kim IY, Kim WJ. Prostate size correlates with fasting blood glucose in non-diabetic benign prostatic hyperplasia patients with normal testosterone levels. J Korean Med Sci. 2011;26(9):1214-8.

41. Cazzaniga W, Ventimiglia E, Alfano M, Robinson D, Lissbrant IF, Carlsson S, Styrke J, Montorsi F, Salonia A, Stattin P. Mini review on the use of clinical Cancer registers for prostate Cancer: the National Prostate Cancer Register (NPCR) of Sweden. Front Med (Lausanne). 2019;6:51.

42. Haggstrom C, Van Hemelrijck M, Zethelius B, Robinson D, Grundmark B, Holmberg L, Gudbjornsdottir S, Garmo H, Stattin P. Prospective study of type 2 diabetes mellitus, anti-diabetic drugs and risk of prostate cancer. Int J Cancer. 2017:140(3):611-7.

\section{Publisher's Note}

Springer Nature remains neutral with regard to jurisdictional claims in published maps and institutional affiliations.
Ready to submit your research? Choose BMC and benefit from:

- fast, convenient online submission

- thorough peer review by experienced researchers in your field

- rapid publication on acceptance

- support for research data, including large and complex data types

- gold Open Access which fosters wider collaboration and increased citations

- maximum visibility for your research: over $100 \mathrm{M}$ website views per year

At BMC, research is always in progress.

Learn more biomedcentral.com/submissions 